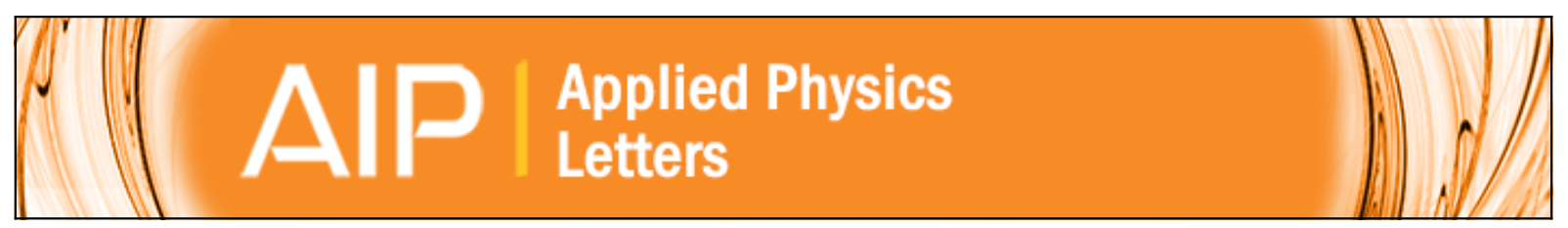

\title{
Effect of temperature on carrier formation efficiency in organic photovoltaic cells
}

Yutaka Moritomo, Kouhei Yonezawa, and Takeshi Yasuda

Citation: Applied Physics Letters 105, 073902 (2014); doi: 10.1063/1.4892611

View online: http://dx.doi.org/10.1063/1.4892611

View Table of Contents: http://scitation.aip.org/content/aip/journal/apl/105/7?ver=pdfcov

Published by the AIP Publishing

\section{Articles you may be interested in}

Annealing temperature dependence of the efficiency and vertical phase segregation of polymer/polymer bulk heterojunction photovoltaic cells

Appl. Phys. Lett. 104, 223906 (2014); 10.1063/1.4880941

Robust carrier formation process in low-band gap organic photovoltaics

Appl. Phys. Lett. 103, 173901 (2013); 10.1063/1.4826187

Effects of molecular interface modification in hybrid organic-inorganic photovoltaic cells

J. Appl. Phys. 101, 114503 (2007); 10.1063/1.2737977

Device annealing effect in organic solar cells with blends of regioregular poly(3-hexylthiophene) and soluble fullerene

Appl. Phys. Lett. 86, 063502 (2005); 10.1063/1.1861123

Vertically segregated hybrid blends for photovoltaic devices with improved efficiency

J. Appl. Phys. 97, 014914 (2005); 10.1063/1.1804613

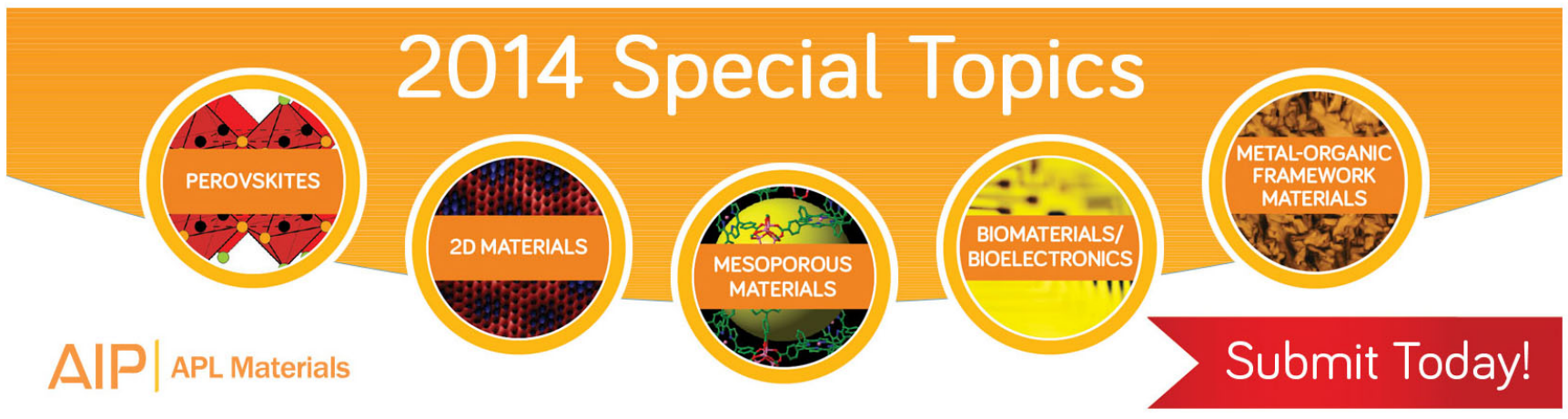




\title{
Effect of temperature on carrier formation efficiency in organic photovoltaic cells
}

\author{
Yutaka Moritomo, ${ }^{1, \text { a) }}$ Kouhei Yonezawa, ${ }^{1}$ and Takeshi Yasuda ${ }^{2}$ \\ ${ }^{1}$ Graduate School of Pure and Applied Science, University of Tsukuba, Tsukuba 305-8571, Japan \\ ${ }^{2}$ Photovoltaic Materials Unit, National Institute for Materials Science (NIMS), Tsukuba 305-0047, Japan
}

(Received 19 February 2014; accepted 25 July 2014; published online 19 August 2014)

\begin{abstract}
The internal quantum efficiency $\left(\phi_{\mathrm{IQ}}\right)$ of an organic photovoltaic cell is governed by plural processes. Here, we propose that $\phi_{\mathrm{IQ}}$ can be experimentally decomposed into carrier formation $\left(\phi_{\mathrm{CF}}\right)$ and carrier transfer $\left(\phi_{\mathrm{CT}}\right)$ efficiencies. By combining femtosecond time-resolved and electrochemical spectroscopy, we clarified the effect of temperature on $\phi_{\mathrm{CF}}$ in a regioregular poly(3-hexylthiophene) (rr-P3HT)/[6,6]-phenyl $\mathrm{C}_{61}$-butyric acid methyl ester blend film. We found that $\phi_{\mathrm{CF}}(=0.55)$ at $80 \mathrm{~K}$ is the same as that $(=0.55)$ at $300 \mathrm{~K}$. The temperature insensitivity of $\phi_{\mathrm{CF}}$ indicates that the electron-hole pairs at the D/A interface are seldom subjected to coulombic binding energy. @ 2014 AIP Publishing LLC. [http://dx.doi.org/10.1063/1.4892611]
\end{abstract}

Organic photovoltaic (OPV) cells with a bulk heterojunction $(\mathrm{BHJ})^{1,2}$ are promising energy conversion devices with flexibility and a low-cost production process, such as the roll-to-roll process. The BHJ active layer, which converts absorbed photons into carriers, is a nanolevel mixture of a donor (D) polymer and acceptor (A) fullerenes. Extensive time-resolved spectroscopy studies ${ }^{3-7}$ have been carried out to reveal the carrier formation dynamics in a poly(3-hexylthiophene) (P3HT)/[6,6]-phenyl $\mathrm{C}_{61}$-butyric acid methyl ester (PCBM) blend film owning to its high power conservation efficiency (PCE $\sim 6 \%) .{ }^{8,9}$ The development of the low-band gap donor polymers, e.g., poly[[4,8-bis[(2-ethylhexyl)oxy]benzo[1,2- $\left.b: 4,5-b^{\prime}\right]$ dithiophene-2,6-diyl][3-fluoro-2-[(2-ethylhexyl)carbonyl]thieno[3,4-b] thiophenediyl]] (PTB7), ${ }^{10}$ further increased PCE to $\sim 9 \%,{ }^{11}$ which motivated intensive pump-probe experiments on low-band-gap BHJs. ${ }^{12-17}$ In the pump-probe experiments, analyses of photoinduced absorption (PIA) reveal the relative numbers of excitons and carriers against delay time $(t)$. One can determine the exciton lifetime and carrier formation time and clarify the carrier formation process. However, interrelation between the carrier formation time and internal quantum efficiency $\left(\phi_{\mathrm{IQ}}\right)$ is still unclear.

The energy conversion of an OPV cell is realized by two successive processes, i.e., (1) carrier formation at the D/A interface and (2) carrier transfer toward the collector electrodes. Therefore, $\phi_{\mathrm{IQ}}$ directly correlates with the carrier formation $\left(\phi_{\mathrm{CF}}\right)$ and carrier transfer $\left(\phi_{\mathrm{CT}}\right)$ efficiencies. $\phi_{\mathrm{CF}}$ is defined as the number of the photoinduced carriers per absorbed photon, while $\phi_{\mathrm{CT}}$ is defined as the number of collected carriers per photoinduced carrier. These efficiencies are important physical quantities in comprehending the device process because $\phi_{\mathrm{IQ}}$ is expressed as $\phi_{\mathrm{CF}} \times \phi_{\mathrm{CT}}$. Significantly, a time-resolved spectroscopy separates the carrier formation process from the subsequent slow carrier transfer process, because the former process is completed within several tens of ps. We proposed that the magnitude of

\footnotetext{
${ }^{\text {a) }}$ Author to whom correspondence should be addressed. Electronic mail: moritomo.yutaka.gf@u.tsukuba.ac.jp.
}

$\phi_{\mathrm{CF}}$ can be determined from the absolute number of photoinduced carriers.

In this Letter, we report the determination of $\phi_{\mathrm{CF}}$ for several OPV cells by combining femtosecond time-resolved and electrochemical spectroscopy. In a regioregular P3HT $(\mathrm{rr}-\mathrm{P} 3 \mathrm{HT}) / \mathrm{PCBM}$ blend film, $\phi_{\mathrm{CF}}(=0.55)$ at $80 \mathrm{~K}$ is the same as that $(=0.55)$ at $300 \mathrm{~K}$. The temperature insensitivity of $\phi_{\mathrm{CF}}$ indicates that the electron-hole pairs at the D/A interface are seldom subjected to coulombic binding energy. We further evaluated $\phi_{\mathrm{IQ}}, \phi_{\mathrm{CF}}$, and $\phi_{\mathrm{CT}}$ of the rr-P3HT/PCBM solar cell against average power $(P)$ in the case of femtosecond pulse laser excitation at $3.1 \mathrm{eV}$.

For the time-resolved spectroscopy, rr-P3HT/PCBM blend film was spin-coated on quartz substrates and annealed for $10 \mathrm{~min}$ at $110^{\circ} \mathrm{C}$ in an inert $\mathrm{N}_{2}$ atmosphere. A solution of rr-P3HT/PCBM (50: 50 wt. \%) was prepared ${ }^{8}$ by dissolving the compounds in $o$-dichlorobenzene $(o$-DCB) $(20 \mathrm{mg}$ polymer in $1 \mathrm{ml}$ solution). The thickness of the blend film was $234 \mathrm{~nm}$. The time-resolved spectroscopy ${ }^{15}$ was carried out in a pump-probe configuration. The blend film was placed on a cold head of a cryostat, whose temperature was controlled with liquid nitrogen. The pump pulse at $3.1 \mathrm{eV}$ was generated as the second harmonics of a regenerative amplified Ti: sapphire laser in a $\beta-\mathrm{BaB}_{2} \mathrm{O}_{4}(\mathrm{BBO})$ crystal. The pulse width and repetition rate were $100 \mathrm{fs}$ and $1000 \mathrm{~Hz}$, respectively. The maximum excitation intensity $\left(I_{\mathrm{ex}}\right)$ was $27 \mu \mathrm{J} / \mathrm{cm}^{2}$. The frequency of the pump pulse was decreased by half $(500 \mathrm{~Hz})$ to provide "pump-on" and "pump-off" conditions. A white probe pulse $(450-1600 \mathrm{~nm})$, generated by self-phase modulation in a sapphire plate was focused on the sample with the pump pulse. The spot sizes of the pump and probe pulses were 4.5 and $2.0 \mathrm{~mm}$ in diameter, respectively. The differential absorption spectrum $(\Delta \mathrm{OD})$ is expressed as $-\log \left(\frac{I_{\mathrm{on}}}{I_{\text {off }}}\right)$, where $I_{\text {on }}$ and $I_{\text {off }}$ are the transmission spectra under the pump-on and pump-off conditions, respectively.

Fig. 1(a) shows $\triangle \mathrm{OD}$ spectra of the rr-P3HT/PCBM blend film at $300 \mathrm{~K}$. The temporal evolution of spectrum is consistent with the literature. ${ }^{3-6}$ The spectrum at $t=1 \mathrm{ps}$ exhibits broad and intense PIA centered at $1.0 \mathrm{eV}$. The PIA at $1 \mathrm{ps}$ is mainly ascribed to donor excitons because the 

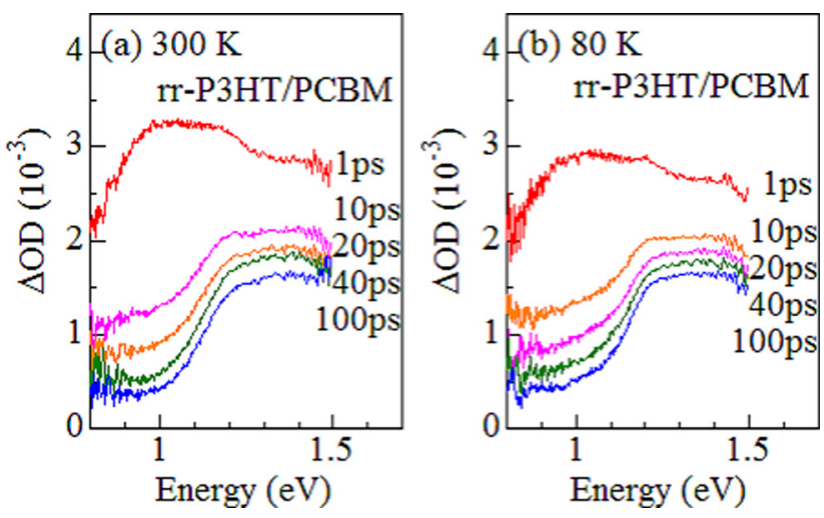

FIG. 1. $\triangle$ OD spectra of rr-P3HT/PCBM blend film at (a) $300 \mathrm{~K}$ and (b) $80 \mathrm{~K}$ against delay time. The excitation power density is $27 \mu \mathrm{J} / \mathrm{cm}^{2}$. Note that the baseline for each spectrum is the same.

spectral profile is similar to that of the neat rr-P3HT film. ${ }^{3-6}$ The exciton component almost disappears at $t=10 \mathrm{ps}$, and a shoulder like structure appears above $1.2 \mathrm{eV}$. The spectral profile slightly changes with $t$ and eventually becomes $t$-independent for $t \geq 40 \mathrm{ps}$. The PIA at $40 \mathrm{ps}$ is ascribed to the donor holes (vide infra). Figure 1(b) shows the $\triangle \mathrm{OD}$ spectra at $80 \mathrm{~K}$. Except for a slight suppression at $t=1 \mathrm{ps}$, their intensities and profiles are essentially the same as those at $300 \mathrm{~K}$.

To evaluate the absorbance $\left(\alpha_{\text {carrier }}\right)$ per carrier, we electrochemically hole-doped on neat rr-P3HT, PTB7, and 2,5di-(2-ethylhexyl)-3,6-bis-( $5^{\prime \prime}$-n-hexy-[2,2',5',2 $\left.2^{\prime \prime}\right]$ terthiophen-5yl)-pyrrolo[3,4-c]pyrrolo-1,4-dione (SMDPPEH) films. The neat rr-P3HT film was spin-coated on an indium-tin-oxide (ITO) glass substrate from $o$-DCB solution and annealed for 10 min at $110^{\circ} \mathrm{C}$ in an inert $\mathrm{N}_{2}$ atmosphere. The neat PTB7 (SMDPPEH) film was spin-coated on the substrate from $o$-DCB (chlorobenzene) solution and was dried in an inert $\mathrm{N}_{2}$ atmosphere. The thicknesses of the rr-P3HT, PTB7, and SMDPPEH films were 86, 96, and $299 \mathrm{~nm}$, respectively. The electrochemical hole-doping was performed against Li metal in propylene carbonate (PC) solution containing $1 \mathrm{~mol} / \mathrm{l}$ $\mathrm{LiClO}_{4}$ in an optical cell with a pair of quartz windows. ${ }^{18,19}$ The active area of the film was $2.25 \mathrm{~cm}^{2}$, and the current was $0.1 \mu \mathrm{A}$. The voltages in the hole-doping process were $\approx 3.4$, $\approx 3.7$, and $\approx 3.6 \mathrm{~V}$ against $\mathrm{Li}$ for the rr-P3HT, PTB7, and SMDPPEH films, respectively. The electrochemical differential absorption $\left(\Delta \mathrm{OD}_{\mathrm{EC}}\right)$ spectrum is expressed as $-\log \left(\frac{I_{\mathrm{doped}}}{I_{\text {non }}}\right)$, where $I_{\text {doped }}$ and $I_{\text {non }}$ are the transmission spectra of the hole-doped and non-doped films, respectively. The carrier density $(n)$ was calculated from the current density and doping time. For convenience of explanation, we roughly evaluated the doping level assuming a film density of $1 \mathrm{~g} / \mathrm{cm}^{3}$. To avoid bipolaron formation, the hole-doping level was lower than $5 \%$ of the monomer (molecule). ${ }^{19}$

The open circles in Fig. 2(a) represent the $\Delta \mathrm{OD}_{\mathrm{EC}}$ spectrum of the neat rr-P3HT film. The shoulder like structure in the spectrum is similar to that in the PIA (solid curve) of the rr-P3HT/PCBM blend film. This indicates that the PIA at 40-100 ps can be ascribed to the donor carriers. The open circles in Fig. 2(b) represent the $\triangle O \mathrm{DD}_{\mathrm{EC}}$ spectrum of the PTB7 film. The sharp peak in the spectrum is similar to that in the PIA (solid curve) of the PTB7/[6,6]-phenyl $\mathrm{C}_{71^{-}}$
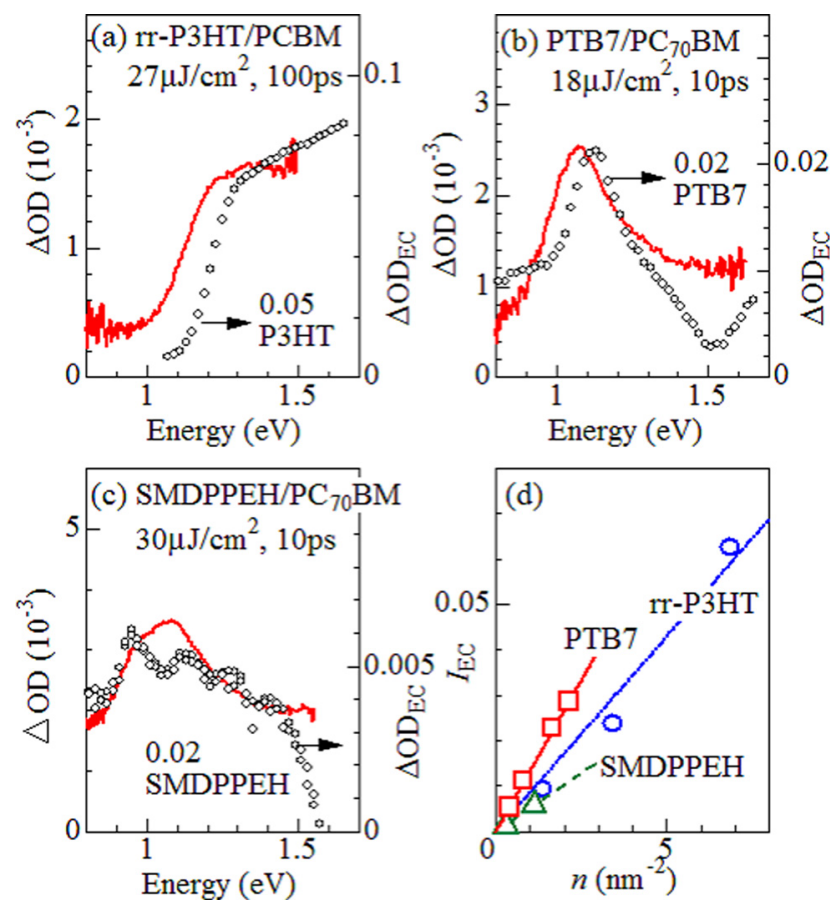

FIG. 2. (a) $\triangle \mathrm{OD}$ spectrum of the rr-P3HT/PCBM blend film at $100 \mathrm{ps}$ together with the electrochemical $\left(\triangle \mathrm{OD}_{\mathrm{EC}}\right)$ spectrum (open circles) of the neat rr-P3HT film. (b) $\Delta \mathrm{OD}$ spectrum (cited from Ref. 15) of the PTB7/PC ${ }_{70} \mathrm{BM}$ blend film at $10 \mathrm{ps}$ together with the $\triangle \mathrm{OD}_{\mathrm{EC}}$ spectrum of the PTB7 film. (c) $\triangle \mathrm{OD}$ spectrum (cited from Ref. 17) of the SMDPPEH/PC $70 \mathrm{BM}$ blend film at $10 \mathrm{ps}$ together with the $\triangle \mathrm{OD}_{\mathrm{EC}}$ spectrum of the SMDPPEH film. (d) Intensity $\left(I_{\mathrm{EC}}\right)$ of the $\Delta \mathrm{OD}_{\mathrm{EC}}$ spectra against carrier density $(n)$ in the neat rr-P3HT, PTB7 and SMDPPEH films. The straight lines are the results of least-squares fitting.

butyric acid methyl ester $\left(\mathrm{PC}_{70} \mathrm{BM}\right)$ blend film. ${ }^{15}$ The open circles in Fig. 2(c) represent the $\triangle \mathrm{OD}_{\mathrm{EC}}$ spectrum of the SMDPPEH film. The rather broad feature in the spectrum is similar to that in the PIA (solid curve) of the SMDPPEH/ $\mathrm{PC}_{70} \mathrm{BM}$ blend film. ${ }^{17}$ Thus, we confirmed correspondences between the $\triangle \mathrm{OD}_{\mathrm{EC}}$ and $\triangle \mathrm{OD}$ spectra.

Fig. 2(d) shows the intensity $\left(I_{\mathrm{EC}}\right)$ of the $\triangle \mathrm{OD}_{\mathrm{EC}}$ spectra against $n$ in the neat rr-P3HT, PTB7, and SMDPPEH films. The magnitudes of $I_{\mathrm{EC}}$ were estimated at $1.3,1.0$, and $1.1 \mathrm{eV}$ for rr-P3HT, PTB7, and SMDPPEH, respectively. In Table I, we summarize the PIA $\left(\alpha_{\text {photon }}\right)$ per absorbed photon, $\alpha_{\text {carrier }}$ and $\phi_{\mathrm{CF}}$ for several BHJ films. $\phi_{\mathrm{CF}}$ for rr-P3HT/PCBM $(\mathrm{PCE}=3.8 \%)$ is 0.55 , while $\phi_{\mathrm{CF}}$ for $\mathrm{PTB} 7 / \mathrm{PC}_{70} \mathrm{BM}(=$ $\left.6.2 \%^{16}\right)$ is $0.55-0.58$. $\phi_{\mathrm{CF}}(=1.51)$ of the SMDPPEH/ $\mathrm{PC}_{70} \mathrm{BM}$ blend film is too high to be feasible, probably due to underestimation of $\alpha_{\text {carrier. Actually, the spin-coated }}$ SMDPPEH film was easily removed in the hole-doping process, which may have caused imperfect hole-doping.

To evaluate $\phi_{\mathrm{IQ}}$ under the femtosecond pulse excitation, we fabricated an rr-P3HT/PCBM solar cell with the structure of ITO / PEDOT:PSS (40 nm)/active layer/LiF (1 nm)/Al $(80 \mathrm{~nm})$. Details of fabrication are described in the literature. $^{6}$ Under AM 1.5 solar-simulated light irradiation of $100 \mathrm{~mW} / \mathrm{cm}^{2}$, the OPV device exhibits a short-circuit current density $\left(J_{\mathrm{SC}}\right)$ of $9.9 \mathrm{~mA} / \mathrm{cm}^{2}$, an open-circuit voltage $\left(V_{\mathrm{OC}}\right)$ of $0.60 \mathrm{~V}$, a fill factor (FF) of 0.64 , a PCE of $3.8 \%$, and $\phi_{\mathrm{IQ}}$ of 0.60 at $3.1 \mathrm{eV}$. The OPV device was placed in a $\mathrm{N}_{2}$-filled box. $\phi_{\mathrm{IQ}}$ was evaluated from the photocurrent $(I)$ against 
TABLE I. PIA $\left(\alpha_{\text {photon }}\right)$ per absorbed photon, absorbance $\left(\alpha_{\text {carrier }}\right)$ per carrier and carrier formation efficiency $\left(\phi_{\mathrm{CF}}\right)$ for several BHJ films. $\alpha_{\mathrm{photon}}$ and $\alpha_{\mathrm{carrier}}$ were estimated by femtosecond time-resolved and electrochemical spectroscopy, respectively. $I_{\text {ex }}$ is the excitation intensity.

\begin{tabular}{|c|c|c|c|c|c|c|}
\hline BHJ & Temperature (K) & $\alpha_{\text {photon }}\left(\mathrm{nm}^{2} /\right.$ photon $)$ & $I_{\mathrm{ex}}\left(\mu \mathrm{J} / \mathrm{cm}^{2}\right)$ & References & $\alpha_{\text {carrier }}\left(\mathrm{nm}^{2} /\right.$ carrier $)$ & $\phi_{\mathrm{CF}}$ \\
\hline rr-P3HT/PCBM & 300 & $4.7 \times 10^{-3}$ & 27 & this work & $8.6 \times 10^{-3}$ & 0.55 \\
\hline rr-P3HT/PCBM & 80 & $4.7 \times 10^{-3}$ & 27 & this work & $8.6 \times 10^{-3}$ & 0.55 \\
\hline PTB7/PC ${ }_{70} \mathrm{BM}$ & 300 & $7.6 \times 10^{-3}$ & 27 & 16 & $1.3 \times 10^{-2}$ & 0.58 \\
\hline $\mathrm{PTB} / \mathrm{PC}_{70} \mathrm{BM}$ & 80 & $7.2 \times 10^{-3}$ & 27 & 16 & $1.3 \times 10^{-2}$ & 0.55 \\
\hline SMDPPEH/PC ${ }_{70} \mathrm{BM}$ & 300 & $7.7 \times 10^{-3}$ & 30 & 17 & $5.1 \times 10^{-3}$ & 1.51 \\
\hline
\end{tabular}
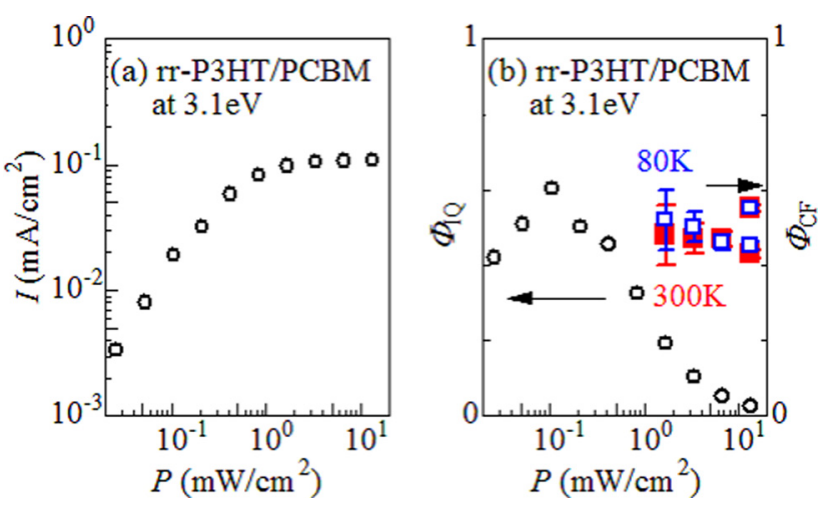

FIG. 3. (a) Photocurrent (I) of rr-P3HT/PCBM OPV device against average power $(P)$ in the case of femtosecond pulse laser excitation at $3.1 \mathrm{eV}$. (b) Internal quantum efficiency $\left(\phi_{\mathrm{IQ}}\right.$ : circles) and carrier formation efficiency ( $\phi_{\mathrm{CF}}$ : squares) against $P$.

average power $(P)$ in the case of femtosecond pulse laser excitation at $3.1 \mathrm{eV}$.

Fig. 3 shows (a) $I$ and (b) $\phi_{\mathrm{IQ}}$ and $\phi_{\mathrm{CF}}$ for the rr-P3HT/ PCBM solar cell against $P$. In the low- $P$ region below 0.5 $\mathrm{mW} / \mathrm{cm}^{2}, \phi_{\mathrm{IQ}}(\sim 0.6)$ is nearly the same $(=0.6)$ as under continuous wave excitation. $\phi_{\mathrm{IQ}}$ gradually decreases with increasing $P$. This is in sharp contrast with the $P$-independence of $\phi_{\mathrm{CF}}$. At $P=14 \mathrm{~mW} / \mathrm{cm}^{2}, \phi_{\mathrm{IQ}}, \phi_{\mathrm{CF}}$, and $\phi_{\mathrm{CT}}$ $\left(=\phi_{\mathrm{IQ}} / \phi_{\mathrm{CF}}\right)$ are estimated to be $0.03,0.55$, and 0.05 , respectively. In other words, $95 \%$ of the photoinduced carriers are annihilated via the electron-hole recombination process. At the weakest excitation condition $\left(P=1.7 \mathrm{~mW} / \mathrm{cm}^{2}\right)$, $\phi_{\mathrm{IQ}}, \phi_{\mathrm{CF}}$, and $\phi_{\mathrm{CT}}$ are estimated to be $0.19,0.48$, and 0.40 , respectively. That is, $40 \%$ of the produced carriers reach the collector electrodes.
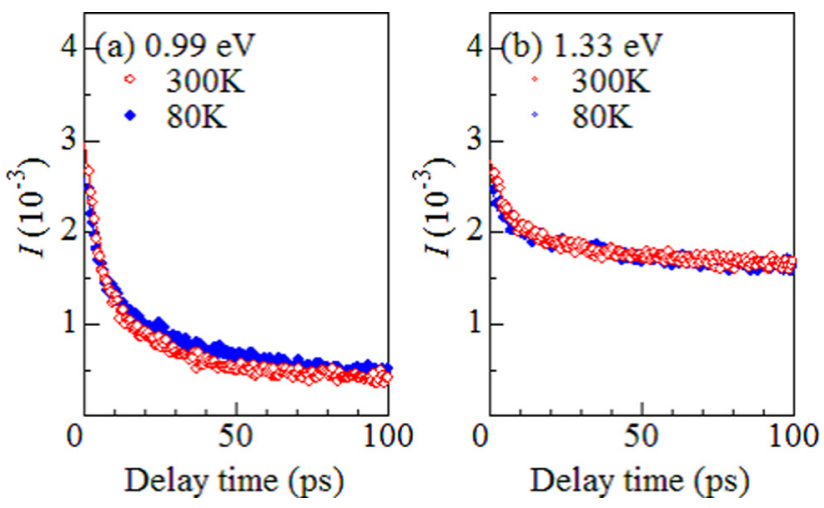

FIG. 4. Temporal evolution of PIA intensity (I) at (a) $0.99 \mathrm{eV}$ and (b) 1.33 $\mathrm{eV}$ in rr-P3HT/PCBM blend film. Open and filled circles represent the data obtained at $300 \mathrm{~K}$ and $80 \mathrm{~K}$, respectively. The solid curves show the results of least-squares fitting with the exponential function $I=A \times \exp (-t / \tau)+C$.
Fig. 4(a) shows the temporal evolution of the exciton component of the PIA [see Fig. 1]. The solid curves show the results of least-squares fitting with the exponential function $I=A \times \exp (-t / \tau)+C$. The constant term $(C)$ is ascribed to the long-lived carrier component. In Table II, we summarize the parameters, $A, \tau$, and $C$. The exciton lifetime $(\tau)$ increases from $12 \mathrm{ps}$ at $300 \mathrm{~K}$ to $17 \mathrm{ps}$ at $80 \mathrm{~K}$. A similar increase in $\tau$ is observed at $1.33 \mathrm{eV}$ [Fig. 4(b)], even though the PIA contains considerable carrier component. The increase in $\tau$ at lower temperatures is reasonable, because it takes a longer time for excitons to reach the D/A interface. The exciton diffusion coefficient $\left(D \propto \tau^{-1}\right)$ at $80 \mathrm{~K}$ is $68 \%-71 \%$ of that at $300 \mathrm{~K}$.

How does the temperature affect $\phi_{\mathrm{CF}}$ in the BHJ system? In the rr-P3HT/PCBM blend film, $\phi_{\mathrm{CF}}(=0.55)$ at $80 \mathrm{~K}$ is the same as that $(=0.55)$ at $300 \mathrm{~K}$ (see Table I). Note that the temperature insensitivity of $\phi_{\mathrm{CF}}$ is observed even at weak excitation condition [Fig. 3(b)]. Similar behavior is observed in $\mathrm{PTB} 7 / \mathrm{PC}_{70} \mathrm{BM}$ blend film; ${ }^{16} \phi_{\mathrm{CF}}=0.58$ at $300 \mathrm{~K}$ and 0.55 at $80 \mathrm{~K}$. These observations are interesting, because electron and hole pair is subjected to a strong coulombic binding energy of several hundred meV upon exciton dissociation if the electron and hole localize on adjacent molecules at the D/A interface. The temperature insensitivity of $\phi_{\mathrm{CF}}$ indicates that the electron-hole pair is seldom subjected to coulombic binding energy. The temperature insensitivity also suggests that the exciton dissociation should not be treated by Marcus theory, ${ }^{20}$ in which the charge-transfer kinetics is governed by displacement of the surrounding molecules.

The high exciton dissociation efficiency in the OPV cell has been ascribed to (1) the delocalized electronic state at the D/A interface $\mathrm{e}^{21-23}$ and (2) excess energy due to vibronically hot excitons. ${ }^{23}$ For example, Kanai and Grossman ${ }^{22}$ investigated the exciton state at $\mathrm{P} 3 \mathrm{HT} / \mathrm{C}_{60}$ interface by $a b$ initio calculation and found that the state has a significant overlap with the lowest unoccupied molecular orbital (LUMO) state on $\mathrm{C}_{60}$. Such a delocalization scenario holds even at low temperatures. On the other hand, the hot exciton scenario does not necessarily explain the high $\phi_{\mathrm{CF}}$ at low

TABLE II. Parameters obtained by least-squares fitting with exponential function, $I=A \times \exp (-t / \tau)+C$.

\begin{tabular}{lcccc}
\hline \hline Energy $(\mathrm{eV})$ & Temperature $(\mathrm{K})$ & $A\left(\times 10^{-3}\right)$ & $\tau(\mathrm{ps})$ & $C\left(\times 10^{-3}\right)$ \\
\hline 0.99 & 300 & 2.1 & 12 & 0.5 \\
0.99 & 80 & 1.7 & 17 & 0.5 \\
1.33 & 300 & 0.9 & 15 & 1.7 \\
1.33 & 80 & 0.7 & 22 & 1.6 \\
\hline \hline
\end{tabular}


temperatures, because the excitons lose their excess energy during the long time required to reach the D/A interface. We suspect that gradient of the fullerene concentration $\left(n_{\mathrm{A}}\right)$ around the D/A interface is responsible for the high $\phi_{\mathrm{CF}}$. Watts et al. ${ }^{24}$ reported that PCBM diffuses into the P3HT domain when a blend film is annealed at $140{ }^{\circ} \mathrm{C}$. In addition, scanning transmission X-ray microscopy (STXM) around the $\mathrm{C} \mathrm{K}$-edge revealed considerable fullerene mixing in the donor-rich domains of $\mathrm{P} 3 \mathrm{HT} / \mathrm{PCBM},{ }^{25} \mathrm{PTB}^{2} / \mathrm{PC}_{70} \mathrm{BM},{ }^{26}$ and $\mathrm{F} 8 \mathrm{~T} 2 / \mathrm{PC}_{70} \mathrm{BM}^{27}$ blend films. The electron-hole pairs should be further delocalized with the $n_{\mathrm{A}}$-gradient because the electrons (holes) tend to be located on the high- $n_{\mathrm{A}}$ (low$\left.n_{\mathrm{A}}\right)$ side.

In conclusion, we experimentally determined $\phi_{\mathrm{CF}}$ for several OPV cells by combining the femtosecond timeresolved and electrochemical spectroscopy. We found that $\phi_{\mathrm{CF}}$ is essentially independent of temperature in the rr$\mathrm{P} 3 \mathrm{HT} / \mathrm{PCBM}$ and PTB7/PC 70 BM blend films. The delocalization scenario convincingly explains the temperature insensitivity of the high $\phi_{\mathrm{CF}}$ values.

This work was supported by Futaba Electronics Memorial Foundation and a Grant-in-Aid for Young Scientists (B) (22750176) from Scientific Research from the Ministry of Education, Culture, Sports, Science and Technology, Japan. We thank Dr. Kamioka for his technical support.

${ }^{1}$ M. Hiramoto, H. Fujiwara, and M. Yokoyama, Appl. Phys. Lett. 58, 1062 (1991).

${ }^{2}$ N. S. Sariciftci, L. Smilowitz, A. J. Heeger, and F. Wudl, Science 285, 1474 (1992).

${ }^{3}$ I.-W. Hwang, D. Moses, and A. J. Heeger, J. Phys. Chem. C 112, 4350 (2008).

${ }^{4}$ J. Guo, H. Ohkita, H. Benten, and S. Ito, J. Am. Chem. Soc. 131, 16869 (2009).
${ }^{5}$ J. Guo, H. Ohkita, H. Benten, and S. Ito, J. Am. Chem. Soc. 132, 6154 (2010).

${ }^{6} \mathrm{~K}$. Yonezawa, M. Ito, H. Kamioka, T. Yasuda, L. Han, and Y. Moritomo, Adv. Opt. Technol. 2012, 316045.

${ }^{7}$ R. A. Marsh, J. M. Hodgkiss, S. Albert-Seifried, and R. H. Friend, Nano Lett. 10, 923 (2010).

${ }^{8}$ M. T. Dang, L. Hirsch, G. Wantz, and J. D. Wuest, Chem. Rev. 113, 3734 (2013).

${ }^{9}$ M. T. Dang, L. Hirsch, and G. Wantz, Adv. Mater. 23, 3597 (2011).

${ }^{10}$ Y. Liang, Z. Xu, J. Xia, S.-T. Tsai, Y. Wu, G. Li, C. Ray, and L. Yu, Adv. Energy Mater. 22, E135 (2010).

${ }^{11}$ Z. He, C. Zhong, S. Su, M. Xu, H. Wu, and Y. Cao, Nat. Photonics 6, 593 (2012).

${ }^{12}$ J. Guo, Y. Liang, J. Szarko, B. Lee, H.-J. Son, B. S. Rolczynski, L. Yu, and L. X. Chen, J. Phys. Chem. B 114, 742 (2010).

${ }^{13}$ J. M. Szarko, J.-C. Guo, B. S. Rolczynski, and L. X. Chen, J. Mater. Chem. 21, 7849 (2011).

${ }^{14}$ B. S. Rolczynski, J. M. Szarko, H. J. Son, Y. Liang, L. Yu, and L. X. Chen, J. Am. Chem. Soc. 134, 4142 (2012).

${ }^{15}$ K. Yonezawa, H. Kamioka, T. Yasuda, L. Han, and Y. Moritomo, Jpn. J. Appl. Phys., Part 1 52, 062405 (2013).

${ }^{16}$ K. Yonezawa, H. Kamioka, T. Yasuda, L. Han, and Y. Moritomo, Appl. Phys. Lett. 103, 173901 (2013).

${ }^{17}$ T. Akaba, K. Yonezawa, H. Kamioka, T. Yasuda, L. Han, and Y. Moritomo, Appl. Phys. Lett. 102, 133901 (2013).

${ }^{18}$ M. Onoda, Y. Manda, S. Morita, and K. Yoshino, Jpn. J. Appl. Phys., Part 131,2265 (1992).

${ }^{19}$ G. Harbeke, D. Baeriswyl, H. Kiess, and W. Kobel, Phys. Scr. T13, 302 (1986).

${ }^{20}$ R. A. Marcus, Rev. Mod. Phys. 65, 599 (1993).

${ }^{21}$ H. Tamura and U. Burghart, J. Am. Chem. Soc. 135, 16364 (2013).

${ }^{22}$ Y. Kanai and J. C. Grossman, Nano Lett. 7, 1967 (2007).

${ }^{23}$ S. D. Dimitrov, A. A. Bakulin, C. B. Nielsen, B. C. Schroeder, J. Du, H. Bronstein, I. McCulloch, R. H. Friend, and J. R. Durrant, J. Am. Chem. Soc. 134, 18189 (2012).

${ }^{24}$ B. Watts, W. J. Belcher, L. Thomsen, H. Ade, and P. C. Dastoor, Macromolecules 42, 8392 (2009).

${ }^{25}$ B. A. Collins, J. R. Tumbleston, and H. Ade, J. Phys. Chem. Lett. 1, 3160 (2010).

${ }^{26}$ B. A. Collins, Z. Li, J. R. Tumbleston, R. Gann, C. R. McNeill, and H. Ade, Adv. Energy Mater. 3, 65 (2013).

${ }^{27}$ Y. Moritomo, T. Sakurai, T. Yasuda, Y. Takeichi, K. Yonezawa, H. Kamioka, H. Suga, Y. Takahashi, Y. Yoshida, N. Inami, K. Mase, and K. Ono, Appl. Phys. Express 7, 052302 (2014). 